\title{
CUESTIONAMIENTOS ÉTICOS RELACIONADOS CON LA TERAPIA GÉNICA PARA EL TRATAMIENTO DE ENFERMEDADES HEREDITARIAS
}

\author{
JOSÉ HENRY OSORIO
}

Manizales, 2010-05-04 (Rev. 2010-09-27)

\section{RESUMEN}

La introducción de secuencias genéticas exógenas denominadas transgenes se denomina terapia génica, y tiene el propósito de corregir alteraciones genotípicas o fenotípicas en el organismo humano. Esta terapia puede realizarse en células somáticas o en células germinales; los cuestionamientos éticos relacionados con la terapia génica somática tienen que ver básicamente con los riesgos potenciales para la salud y el consentimiento informado, mientras que la terapia génica en células germinales tiene el potencial de afectar permanentemente a futuras generaciones de personas. Debido a que la terapia génica involucra mucho más que la simple alteración de las secuencias genéticas, esta revisión presenta los principales problemas éticos asociados con la terapia génica para enfermedades hereditarias.

\section{PALABRAS CLAVE:}

Terapia génica, consideraciones éticas, enfermedades hereditarias.

\section{ETHICAL QUESTIONING RELATED TO GENE THERAPHY FOR INHERITED DISEASES TREATMENT}

\section{ABSTRACT}

The introduction of exogenous genetic sequences named transgenes is known as gene therapy and has the purpose of correcting genotypic and phenotypic alterations in the human organism. This therapy can be carried out in somatic cells or in germinal cells. The ethical questioning related to somatic gene therapy has to do basically with the potential risks for health and the informed consent while germ-line gene therapy has the potential to affect permanently future generations. Since genic therapy involves much more than the simple alteration of genetic sequences, this revision presents the main ethical problems associated with gene therapy for inherited disease.

Key words: gene therapy, ethical issues, inherited diseases.

\section{INTRODUCCIÓN}

La secuenciación del genoma humano ha permitido conocer las causas y las bases moleculares de un gran número de enfermedades humanas (Lander et al., 2001; Venter et al., 2001), lo que ha impulsado a la biomedicina a desarrollar técnicas y terapias celulares y génicas, para el tratamiento de diferentes enfermedades (Reich \& Lander, 2001). La terapia génica tiene como objetivo la corrección de anormalidades genotípicas o fenotípicas, o la introducción en el organismo vivo de células con funciones nuevas, es decir, se da en el individuo la modificación genética. Para tal fin, son introducidos en el organismo secuencias genéticas exógenas denominadas transgenes, las cuales pueden modificar las células somáticas o las células germinales; en el primer caso, la modificación genética solo afecta al paciente que recibe los transgenes, mientras que en el segundo caso se pueden afectar las generaciones futuras del individuo (Brody \& Crystal, 1994; Mitani et al., 1993).

Además de las enfermedades genéticas, actualmente el concepto de terapia génica se extiende a otras enfermedades como el cáncer, mediante el uso de vectores oncolíticos (Alemany, 2007) o genes suicidas, así como a enfermedades infecciosas como en el caso del sida (Roberts, 2006). En la terapia génica dirigida a células somáticas, se puede realizar terapia génica extrayendo células del paciente, para luego manipularlas genéticamente y retornarlas al cuerpo del individuo; esto es lo que se denomina tratamiento ex vivo. La manipulación genética también puede darse directamente en el cuerpo del individuo, y por eso se denomina in vivo (Lazo \& Tsichlis, 1990; Laufs et al., 2003). En ambos casos, la terapia génica busca llevar, de manera adecuada, material genético terapéutico a las células diana, es decir, transferir genes (Braas et al., 1996). Por eso, los objetivos fundamentales de la terapia génica deben ser la efectividad de la transferencia génica, la 
especificidad de la transferencia al tipo o tipos celulares diana y la persistencia del material genético transferido.

Dentro de las estrategias de manipulación genética con finalidad terapéutica, se tiene la adición génica, basada en la introducción de una copia correcta del gen funcional que dé lugar a la expresión de la proteína diana en el tejido adecuado con niveles suficientes para que pueda desarrollar su función apropiadamente. La supresión génica tiene como objetivo reducir o anular la expresión de un determinado gen y la corrección génica, y busca corregir un gen alterado por un gen correcto (Morgan \& Anderson, 1993). El objetivo final de la investigación en terapia génica consiste en trasladar a la clínica las estrategias que han dado buenos resultados en los ensayos en modelos preclínicos, luego de lo cual se da inicio a los ensayos clínicos en fase I, fase II, fase III y fase IV.

El primer ensayo aprobado de terapia génica se realizó en 1989, y desde entonces hasta la fecha se han desarrollado y aplicado 1.579 protocolos. El año 2006 se destaca por ser el de mayor número, con 117 protocolos aprobados. En el año 2009, 40 de estos protocolos fueron desarrollados. La distribución por países es la siguiente: Estados Unidos, 1.010 (64\%); Europa, 467 (29,6\%); Asia, 58 (3,7\%); Australasia, 30 (1,9\%); África, $1(0,1 \%)$, varios países, $13(0,8 \%)$. Ahora bien, 952 de estos protocolos $(60,3 \%)$ se encuentran en fase I, $299(18,9 \%)$ se encuentran en fase I/II, $258(16,3 \%)$ se encuentran en fase II, $13(0,8 \%)$ están en fases II/III, $53(3,4 \%)$ se encuentran en fase III y solamente el $0,1 \%$, es decir 2 protocolos, han llegado a la fase IV (Gen therapy clinical trials world wide, 2010). Solo hasta el año 2008 pudo ser comercializado el primer producto de terapia génica, Gendicine (Adp53), en los países asiáticos, y se está empezando a usar para el tratamiento del cáncer (Räty et al., 2008; Yang, 2010). Por lo anteriormente expuesto, la terapia génica tiene cuestionamientos e implicaciones éticas relacionadas con riesgos potenciales para la salud del individuo que la recibe, problemas de consentimiento informado y responsabilidades hacia futuras personas (Dettweiler \& Simon, 2001).

\section{VÍAS DE ADMINISTRACIÓN GÉNICA}

Para la terapia génica somática in vivo, la transducción de las células diana se hace mediante vectores directamente en el paciente, y su éxito dependerá de la especificidad del vector por la célula diana y su eficiencia de transducción (Hoatlin, 1995). Los vectores se clasifican en virales y no virales. Los virales son los más eficientes para la transferencia del material genético, pero presentan complicaciones por su alta respuesta inmune, alto costo, dificultades técnicas para su producción y problemas de bioseguridad (Solly, 2003). Entre los vectores virales más utilizados están los retrovirus, adenovirus, virus adenoasociados, lentivirus y virus herpes (Heilbronn \& Weger, 2010). A la fecha, de 1.579 protocolos, $379(24 \%)$ utilizan adenovirus, $333(21,1 \%)$ utilizan retrovirus, $98(6,2 \%)$ utilizan vaccinia virus, $66(4,2 \%)$ utilizan poxvirus y 24 protocolos $(1,5 \%)$ utilizan lentivirus, entre otros (Gen therapy clinical trials world wide, 2010).

La terapia génica no viral transporta el gen mediante métodos físico-químicos, lo que facilita su producción, con poca o nula respuesta inmune y sin limitación en cuanto al gen de interés, pero tiene todavía como inconvenientes la poca especificidad por las células diana y su baja eficiencia de transducción. Los métodos de transferencia química permiten la formación de complejos con el ADN por interacción de cargas, mientras que los de transferencia física permiten la entrada del ADN por sobrepresión. Tal es el caso de la electroporación, la biobalísitica y el sistema hidrodinámico (Mir, 2005; Porteus, 2006). Por tanto, las características buscadas para los vectores en terapia génica son la alta eficiencia de transferencia del material genético utilizado, la especificidad por el órgano diana con baja o nula inmunogenicidad, la gran duración de la expresión del transgen, así como la fácil producción, purificación y manipulación genética, con bajo precio de fabricación y controles accesibles para su producción industrial (Hart, 2010; Escors \& Breckpot, 2010). La terapia génica que involucra células germinales no ha sido implementada todavía en humanos, razón por la cual no se describen sus procedimientos en esta revisión.

\section{TERAPIA GÉNICA PARA EL TRATAMIENTO DE ENFERMEDADES HEREDITARIAS}

En el año de 1990 se utilizó por primera vez la terapia génica para el tratamiento de una enfermedad genética. El tratamiento de la deficiencia severa combinada por adenosina deaminasa (SCID-ADA) se realizó en dos pacientes mediante un vector retroviral con el gen ADA, transfectándolo en células T de sangre, con buenos resultados (Anderson, Blaese \& Culver, 1990). Desde entonces se han realizado otros 5 ensayos con 11 pacientes y diferentes vectores y protocolos (Ariga, 2001). Aunque solamente unos pocos ensayos clínicos han llegado a la fase III, entre estos se cuentan la inmunodeficiencia severa combinada (SCID)-X1 (Cavazzana-Calvo, 2005; Hacein-Bey-Abina, Fischer \& Cavazzana-Calvo, 2002) y SCID-ADA (Anderson, Blaese \& Culver, 1990), la deficiencia de ornitina transcarbamilasa (OCT) (Raper \& McClane, 2002; Raper et al., 2002), así como las hemofilias A y B (Manno, 2002; Walsh, 2003). Otros protocolos se han implementado para enfermedades hereditarias como la fibrosis quística (Griesenbach, 2002), las mucopolisacaridosis y 
la enfermedad de Gaucher, así como algunas aminoacidopatías, como la fenilcetonuria, tirosinemia tipo I y homocistinuria (Cheng \& Smith, 2003; Nguyen \& Ferry, 2007). Sin embargo, no todos los tratamientos han dado buenos resultados y algunos han resultado en complicaciones para los pacientes o su muerte (Hacein-Bey-Abina, Fischer \& Cavazzana-Calvo, 2002; Hacein-Bey-Abina et al., 2003b; Raper et al., 2003).

\section{RIESGOS DE LA TERAPIA GÉNICA PARA EL TRATAMIENTO DE ENFERMEDADES HEREDITARIAS}

Una estrategia de terapia génica ex vivo con un retrovirus en células madre del propio paciente, se ensayó en el año 2000 con 11 pacientes que padecían la enfermedad SCID-X1. Esta debió suspenderse en el año 2002, por la aparición de niveles anormales de glóbulos blancos en dos pacientes (Hacein-Bey-Abina, Fischer \& Cavazzana-Calvo, 2002). El incremento descontrolado de células del sistema inmune provocó una leucemia en los pacientes afectados, debido a la integración del genoma del vector en la región del gen MLO2, un oncogen frecuentemente sobreexpresado en leucemias de células T (Hacein-Bey-Abina, 2003b). Otro ejemplo de protocolo que implicó riesgos para las personas tratadas fue el de la deficiencia de ornitina transcarbamilasa (OTC), en el cual se utilizó un vector adenovirus de segunda generación, sin las regiones E1 y E4.

A pesar de que los estudios en ratones y primates no dieron buenos resultados, se decidió utilizarlos en ensayos clínicos con humanos (Raper, 1998), por lo cual se inició la aplicación del protocolo a 17 pacientes con deficiencia de OTC. Por desconocer la dosis adecuada, se administraron dosis desde $2 \times 10^{9}$ hasta $6 \times 10^{11}$ partículas físicas por kilogramo. 7 pacientes mostraron actividad para el transgen, pero todos los pacientes presentaron respuesta inmune celular y alta respuesta inmune humoral contra el virus, y por esto se concluyó que la dosis era inadecuada para obtener la respuesta esperada (Raper, et al., 2002). Posteriormente, se aplicó el protocolo a una persona de 18 años, aplicando directamente el vector en la arteria hepática a una dosis de $3,8 \times 10^{13}$ partículas formadoras de placa por kilogramo. Este paciente desarrolló, 18 horas después de recibir el tratamiento, una fuerte respuesta inflamatoria sistémica, coagulación intravascular y fallo multisistémico, lo que le ocasionó la muerte 98 horas después de recibir el vector (Raper, et al., 2003).

\section{CUESTIONAMIENTOS ÉTICOS DE LA TERAPIA GÉNICA: DEL EXPERIMENTO TUSKEGEE AL CASO DE JESSE GELSINGER}

Se podría hacer un paralelo entre dos situaciones de investigación biomédica que involucraron humanos y dejaron profundas huellas en el campo de la bioética. La primera fue el estudio clínico llevado a cabo entre 1932 y 1972 en Tuskegee, Alabama (Estados Unidos), en donde 399 sujetos con sífilis fueron estudiados para observar la progresión natural de la enfermedad durante 40 años sin tratamiento, comparado con un grupo de 201 hombres sanos. Estos sujetos no dieron su consentimiento informado, no fueron informados de su diagnóstico y fueron engañados al decirles que tenían "mala sangre" y que podrían recibir tratamiento médico gratuito, transporte gratuito a la clínica, comidas y un seguro de sepelio en caso de fallecimiento si participaban en el estudio (Katz, 2008).

A pesar de que para el año 1947 la penicilina se había convertido en el tratamiento de elección para la sífilis, los responsables del estudio no trataron a los pacientes infectados y ocultaron la información disponible sobre la penicilina para continuar estudiando la evolución de la enfermedad. Además, forzaron a los sujetos para que evitaran el tratamiento con penicilina, que ya estaba siendo utilizada con otros enfermos del lugar, e implementaron prácticas como la punción lumbar, haciéndoles creer a los participantes que esto hacía parte del tratamiento. El estudio continuó hasta 1972 y terminó con un saldo de 28 pacientes que murieron de sífilis y otros 100 que murieron de complicaciones médicas relacionadas; similarmente, 40 mujeres de la comunidad terminaron infectadas y 19 niños que contrajeron la enfermedad al nacer (White, 2008).

Por el contrario, la segunda situación, relacionada directamente con la terapia génica, fue el caso de Jesse Gelsinger, un voluntario de 18 años de edad, tratado para corregir la deficiencia severa de ornitina transcarbamilasa, un defecto del ciclo de la urea, y para lo cual recibió en septiembre de 1999, la dosis más alta de un vector adenoviral vía intraportal $\left(3,8 \times 10^{13}\right.$ partículas virales por kilogramo), lo que provocó que otros órganos aparte del hígado fueran modificados con el vector, lo que pudo haber sido el factor determinante que le provocó una respuesta inmune exacerbada y le causó un colapso agudo del sistema respiratorio y un fallo multisistémico inflamatorio que le provocó la muerte (Savulescu, 2001). Además, en el análisis de la autopsia se encontró que la médula ósea de Gelsinger estaba dañada probablemente debido a una infección mediada por otro virus, que se pudo producir durante o incluso antes del tratamiento experimental, y que pudo desencadenar la extraordinaria respuesta inmune que acabó con su vida. 
Vale la pena mencionar que este paciente sufría una forma intermedia de la enfermedad, la cual podía ser manejada con dieta y suplementos farmacológicos, por eso el protocolo experimental para el cual Jesse se prestó voluntariamente no tenía posibilidad de proveer ningún beneficio a él o a los otros voluntarios, ya que el protocolo estaba diseñado sólo para probar la seguridad de un tratamiento que podría ser usado en bebés con la forma letal de OTC. A pesar de que los estudios en ratones y primates no dieron buenos resultados, se decidió utilizarlos en ensayos clínicos con humanos, ya que los investigadores citaron más de 20 experimentos en ratones para probar la eficacia del tratamiento y una docena de estudios de seguridad en ratones, monos Rhesus y mandriles, sin tener en cuenta que varios monos Rhesus murieron como consecuencia de reacciones inmunológicas intensas a altas dosis de adenovirus, similares a la reacción que finalmente presentó el paciente (Savulescu, 2001).

Luego de que el Comité Asesor sobre ADN Recombinante (RAC) del Instituto Nacional de Salud (NIH) y la Administración de Alimentos y Drogas (FDA) de los Estados Unidos ordenaran una investigación sobre el caso, se informó que el hígado del paciente no funcionaba adecuadamente al momento de la inyección de adenovirus y que él no debió ser elegible para el estudio, dejando entrever que no se previeron los efectos secundarios serios o potencialmente mortales y que no se realizó un examen médico exhaustivo buscando la posible presencia de otra infección por otro virus. Además, el documento de consentimiento informado que el paciente firmó era distinto del originalmente aprobado por el NIH cuando éste revisó los protocolos, ya que la nueva versión de consentimiento informado no hacía mención de las reacciones adversas del sistema inmune al adenovirus, las cuales implicaron la muerte de los primates de experimentación (Savulescu, 2001).

Los científicos ocultaron a la FDA que otros dos voluntarios sometidos previamente al mismo ensayo habían sufrido efectos secundarios tan graves que, de haber sido notificados, hubieran supuesto la inmediata suspensión del ensayo. Se puso de manifiesto que la RAC había recomendado con anterioridad que el vector fuera suministrado por vía endovenosa, pero los investigadores la depositaron directamente en el hígado y, a la vez, subestimaron la virulencia del vector, ya que según ellos había estado almacenado durante 25 meses, por lo que justificaron una dosis tan alta para utilizar. Se develó también el conflicto de intereses de uno de los gestores del protocolo, ya que era dueño de una compañía que poseía los derechos de cualquier descubrimiento hecho por él en su laboratorio, y esa compañía podía dejar que el laboratorio hiciera las pruebas clínicas antes de decidir hacer inversiones; además, esa compañía realizó una inversión financiera en la variación del adenovirus que se desarrolló y probó en ese paciente, durante las pruebas de terapia de genes en humanos, buscando un adenovirus que hubiera sido muy rentable si hubiera tenido éxito la aplicación del protocolo.

También se planteó el hecho de que algunos de los voluntarios para este estudio fueron reclutados de forma coercitiva, usando sitios en la Web que detallaban el uso de bajas dosis y resultados promisorios de la terapia. Se planteó que este tipo de ofertas, puestas en lugares donde puede acceder una población sensible a los problemas de vivir con una enfermedad genética, crea dudas sobre cómo obtener voluntarios verdaderamente informados para ser usados en la experimentación (Savulescu, 2001). Los dos estudios anteriormente mencionados son similares porque plantean dilemas éticos, desde una época en la cual no existían reglas para la realización de experimentación en humanos hasta una época en que todos los planteamientos éticos y las normas estaban claramente trazados por el código de Núremberg (1947) y la declaración de Helsinki (1964), y que plantean los principios éticos para las investigaciones médicas en seres humanos, buscando que el bienestar de las personas que participan en la investigación tenga siempre primacía sobre todos los otros intereses.

En ambos estudios, el experimento Tuskegee y el caso de Jesse Gelsinger, a pesar de la diferencia en los objetivos propuestos y del tiempo en que se desarrollaron, se plantean irregularidades procedimentales censurables éticamente. A pesar de que en ambos casos se procedió por medio de la creación y reforzamiento de entidades estatales para analizar la problemática de fondo y para tomar medidas correctivas (NIH Report, 2002; Department of Health and Human Services), esto produjo una caída generalizada de la confianza pública en el potencial de la investigación biomédica y biotecnológica, así como un reforzamiento de las actitudes de sospecha indiscriminada hacia los intereses promovidos por la industria biotecnológica, clasificándolos negativamente como agentes sin escrúpulos.

\section{CONCLUSIÓN}

Los cuestionamientos éticos que surgen de la revisión cualitativa de la bibliografía con relación al uso de la terapia génica, para el tratamiento de enfermedades hereditarias, dejan claro que se deben realizar de manera exhaustiva ensayos previos en animales de experimentación para predecir los inconvenientes de la terapia en humanos o la variación entre paciente y paciente; es 
imprescindible la obtención del consentimiento informado por parte de los pacientes, pero los pacientes deben estar verdaderamente informados acerca de los procedimientos a los que van a ser sometidos, los antecedentes, riesgos y limitaciones de los procedimientos, y en ningún caso se deben modificar los consentimientos aprobados previamente por los comités establecidos de bioética.

Siempre debe cuestionarse de manera juiciosa el uso de tipos de voluntarios para las pruebas que se van a realizar, tratando de cerciorarse de que son adecuados para los protocolos que se piensan ejecutar; además, los medios utilizados para la consecución de voluntarios para los estudios experimentales deben estar plenamente establecidos, y las reglas de juego deben ser claras a fin de evitar la coerción o el engaño para captar voluntarios en los trabajos de experimentación; la modificación intencional de los protocolos y el engaño como norma para los participantes en los estudios no puede permitirse, toda vez que los resultados pueden ser funestos para los mismos.

Un control gubernamental e institucional ineficientes pueden ser el resultado de diferentes negociaciones entre los equipos de trabajo y los entes de control, lo que va en detrimento de los sujetos participantes; y finalmente, debe aclararse si los investigadores participantes presentan o no conflicto de intereses, y de tenerlos deben ser inhabilitados para participar en los estudios, con miras a evitar la manipulación sesgada de los procedimientos que se van a realizar.

\section{BIBLIOGRAFÍA}

- Alemany, R. (2007). "Cancer selective adenoviruses". Mol Aspects Med, 28(1), 42-58.

- Ali, M.; Lemoine, N.R. \& Ring, C. J. (1994). "The use of DNA viruses as vectors for gene therapy". Gene Ther, 1(6), 367-384.

- Anderson, W. F.; Blaese, R. M. \& Culver, K. (1990). "The ADA human gene therapy clinical protocol: Points to Consider response with clinical protocol". Hum Gene Ther, 1(3), 331-362.

- Ariga, T.; Oda, N.; Yamaguchi, K.; Kawamura, N.; Kikuta, H.; Taniuchi, S. et al. (2001). "Tcell lines from 2 patients with adenosine deaminase (ADA) deficiency showed the restoration of ADA activity resulted from the reversion of an inherited mutation". Blood, 97(9):2896-2899.

- Ashorn, M.; Pitkänen, S.; Salo, M. K. \& Heikinheimo, M. (2006). "Current strategies for the treatment of hereditary tyrosinemia type I". Paediatr Drugs, 8(1), 47-54.

- Braas, G.; Searle, P. F.; Slater, N. K. H. \& Lyddiatt, A. (1996). "Strategies for the isolation and purification of retroviral vectors for gene therapy". Bioseparation, 6(4), 211-228.

- Brody, S.L. \& Crystal, R. G. (1994). "Adenovirus-mediated in vivo gene transfer". Ann N Y Acad Sci, 716, 90-101.

- Cabrera-Salazar, M. A.; Novelli, E. \& Barranger, J. A. (2002). "Gene therapy for the lysosomal storage disorders". Curr Opin Mol Ther, 4, 1464-8431.

- Cavazzana-Calvo, M.; Lagresle, C.; Hacein-Bey-Abina, S.; Fischer, A. (2005). "Gene therapy for severe combined immunodeficiency". Annu Rev Med, 56, 585-602.

- Cavazzana-Calvo, M.; Hacein-Bey, S.; De Saint Basile, G.; Gross, F.; Yvon, E.; Nusbaum, P. et al. (2000). "Gene therapy of human severe combined immunodeficiency (SCID)-X1 disease". Science, 288, 669-672.

- Cheng, S. H. \& Smith, A. E. (2003). "Gene therapy progress and prospects: gene therapy of lysosomal storage disorders". Gene Ther, 10, 1275-1281.

- Cheng, S. H.; Ziegler, R.; Barbon, S.; Disnick, R.; Schuchman, E. (2004). "Efficacy of AAVmediated expression of ASM in Niemann-Pick B mice". J Inherit Metab Dis, 27(suppl 1), 162.

- Department of health and human services. Part 46. "Protection of human subjects". http://www.hhs.gov/ohrp/humansubjects/guidance/45cfr46.htm.

- Dettweiler, U. \& Simon, P. (2001). "Points to consider for ethics committees in human gene therapy trials". Bioethics, 15(5-6), 491-500.

- Escors, D. \& Breckpot, K. (2010). "Lentiviral vectors in gene therapy: their current status and future potential". Arch Immunol Ther Exp (Warsz), 58(2), 107-119.

- "Gen therapy clinical trials world wide". (2010). J Gene Med. http://www.wiley.co.uk/genmed/clinical/

- Griesenbach, U.; Ferrari, S.; Geddes, D. M. \& Alton, E.W.F.W. (2002). "Gene therapy progress and prospects: cystic fibrosis". Gene Ther, 9,1344-1350.

- Hacein-Bey-Abina, S.; Fischer, A. \& Cavazzana-Calvo, M. (2002). "Gene therapy of X-linked severe combined immunodeficiency". Int J Hematol, 76(4), 295-298. 
- Hacein-Bey-Abina, S.; Von Kalle, C.; Schmidt, M.; Le Deist, F.; Wulffraat, N.; McIntyre, E. et al. (2003a). "A serious adverse event after successful gene therapy for X-linked severe combined immunodeficiency". N Engl J Med, 348(3), 255-256.

- Hacein-Bey-Abina, S.; Von Kalle, C.; Schmidt, M.; McCormack, M. P.; Wulffraat, N.; Leboulch, P. et al. (2003b). "LMO2-associated clonal T cell proliferation in two patients after gene therapy for SCID-X1". Science, 302(5644), 415-419.

- Hart, S. L. (2010). "Multifunctional nanocomplexes for gene transfer and gene therapy". Cell Biol Toxicol, 26(1), 69-81.

- Heilbronn, R. \& Weger, S. (2010). "Viral vectors for gene transfer: current status of gene therapeutics". Handb Exp Pharmacol, 197, 143-170.

- Hoatlin, M. E.; Kozak, S. L.; Spiro, C. \& Kabat, D. (1995). "Amplified and tissue directed expression of retroviral vectors using ping-pong techniques". J Mol Med, 73(3), 113-120.

- Katz, R. V.; Green, B. L.; Kressin, N. R.; Kegeles, S. S.; Wang, M. Q.; James, S. A. et al. (2008). "The legacy of the Tuskegee Syphilis Study: assessing its impact on willingness to participate in biomedical studies". J Health Care Poor Underserved, 19(4):1168-1180.

- Kay, M. A.; Manno, C. S.; Ragni, M. V.; Larson, P. J.; Couto, L. B.; McClelland, A. et al. (2000). "Evidence for gene transfer and expression of factor IX in haemophilia B patients treated with an AAV vector". Nat Genet, 24(3), 257-261.

- Lander, E.S.; Linton, L.M.; Birren, B.; Nusbaum, C.; Zody, M.C.; Baldwin, J. et al. (2001). "Initial sequencing and analysis of the human genome". Nature, 409, 860-921.

- Laufs, S.; Gentner, B.; Nagy, K. Z.; Jauch, A.; Benner, A.; Naundorf, S. et al. (2003). "Retroviral vector integration occurs in preferred genomic targets of human bone marrowrepopulating cells". Blood, 101(6), 2191-2198.

- Lazo, P. A. \& Tsichlis, P. N. (1990). "Biology and pathogenesis of retroviruses". Semin Oncol, 17(3), 269-294.

- Manno, C. S. (2002). "Gene therapy for bleeding disorders". Curr Opin Hematol, 9(6), 511515.

- Manno, C. S.; Chew, A. J.; Hutchison, S.; Larson, P. J.; Herzog, R. W.; Arruda, V. R. et al. (2003). "AAV-mediated factor IX gene transfer to skeletal muscle in patients with severe hemophilia B". Blood, 101(8), 2963-2972.

- Manno, C. S.; Pierce, G. F.; Arruda, V. R.; Glader, B.; Ragni, M.; Rasko, J. J. et al. (2006). "Successful transduction of liver in hemophilia by AAV-Factor IX and limitations imposed by the host immune response". Nat Med, 12(3), 342-347.

- Mitani, K.; Clemens, P. R.; Moseley, A. B. \& Caskey, C. T. (1993). "Gene transfer therapy for heritable disease: cell and expression targeting". Philos Trans R Soc Lond B Biol Sci, 339(1288), 217-224.

- Mir, L. M.; Moller, P. H.; André, F. \& Gehl, J. (2005). "Electric pulse-mediated gene delivery to various animal tissues". Adv Genet, 54, 83-114.

- Morgan, R. A. \& Anderson, W. F. (1993). "Human gene therapy". Annu Rev Biochem 62, 191-217.

- Morsy, M. A.; Mitani, K.; Clemens, P. \& Caskey, C. T. (1993). "Progress toward human gene therapy". JAMA, 270(19), 2338-2345.

- NIH Report. (2002). "Assesment of adenoviral vector safety an toxicity: report of the National Institutes of Health Recombinant DNA Advisory Committee". Hum Gene Ther, 13, 3-13.

- Nguyen, T. H. \& Ferry, N. (2007). "Gene therapy for liver enzyme deficiencies: what have we learned from models for Crigler-Najjar and tyrosinemia?". Expert Rev Gastroenterol Hepatol, $1(1), 155-171$.

- O'Neal, W.K. \& Beaudet, A. L. (1994). "Somatic gene therapy for cystic fibrosis". Hum Mol Genet, 3 Spec No.,1497-1502.

- Porteus, M. H. (2006). "Mammalian gene targeting with designed zinc finger nucleases". Mol Ther, 13(2), 438-446.

- Porteus, M. H. \& Carroll, D. (2005). "Gene targeting using zinc finger nucleases". Nat Biotechnol, 23(8), 967-973.

- Porteus, M. H.; Connelly, J. P. \& Pruett, S. M. (2006). "A look to future directions in gene therapy research for monogenic diseases". PLoS Genet, 2(9), e133.

- Raper, S. E.; Wilson, J. M.; Yudkoff, M.; Robinson, M. B.; Ye, X. \& Batshaw, M. L. (1998). "Developing adenoviral-mediated in vivo gene therapy for ornithine transcarbamylase deficiency". J Inherit Metab Dis, 21(Suppl 1), 119-137.

- Raper, S. E. \& McClane, S. J. (2002). "Gene transfer strategies for metabolic diseases". World J Surg, 26(7), 838-842.

- Raper, S.E.; Yudkoff, M.; Chirmule, N.; Gao, G. P.; Nunes, F.; Haskal, Z. J. et al. (2002). "A pilot study of in vivo liver-directed gene transfer with an adenoviral vector in partial ornithine transcarbamylase deficiency". Hum Gene Ther, 13(1), 163-175. 
- $\quad$ Raper, S. E.; Chirmule, N.; Lee, F. S.; Wivel, N. A.; Bagg, A.; Gao, G. P. et al. (2003). "Fatal systemic inflammatory response syndrome in a ornithine transcarbamylase deficient patient following adenoviral gene transfer". Mol Genet Metab, 80(1-2), 148-58.

- Räty, J. K.; Pikkarainen, J. T.; Wirth, T. \& Ylä-Herttuala, S. (2008). "Gene therapy: the first approved gene-based medicines, molecular mechanisms and clinical indications". Curr Mol Pharmacol, 1(1), 13-23.

- Reich, D.E. \& Lander, E. S. (2001). "On the allelic spectrum of human disease". Trends Genet, 17(9), 502-510.

- Roberts, D. M.; Nanda, A.; Havenga, M. J.; Abbink, P.; Lynch, D. M.; Ewald, B.A. et al. (2006). "Hexon-chimaeric adenovirus serotype 5 vectors circumvent pre-existing anti-vector immunity". Nature, 441(7090), 239-243.

- Savulescu, J. (2001). "Harm, ethics comities and gene therapy death". J Med Ethics, 27, 148-150.

- Shi, J. \& Zheng, D. (2009). "An update on gene therapy in China". Curr Opin Mol Ther, 11(5), 547-553.

- Solly, S. K.; Trajcevski, S.; Frisen, C.; Holzer, G. W.; Nelson, E.; Clerc, A. et al. (2003). "Replicative retroviral vectors for cancer gene therapy". Cancer Gene Ther 10(1), 30-39.

- Venter, J.C.; Adams, M.D.; Myers, E.W.; Li, P.W.; Mural, R.J.; Sutton G.G. et al. (2001). "The sequence of the human genome". Science, 291,1304-1351.

- Walsh, C. E. (2003). "Gene therapy progress and prospects: gene therapy for the hemophilias". Gene Ther, 10, 999-1003.

- White, R. M. (2008). "Challenges in a narrative about the Tuskegee Study of Untreated Syphilis". J Transcult Nurs, 19(2):105-106.

- Yang, Z. X.; Wang, D.; Wang, G.; Zhang, Q.H.; Liu, J. M.; Peng, P. et al. (2010). "Clinical study of recombinant adenovirus-p53 combined with fractionated stereotactic radiotherapy for hepatocellular carcinoma". J Cancer Res Clin Oncol, 136(4), 625-630.

1. Laboratorio de Bioquímica Clínica y Patología Molecular. Departamento de Ciencias Básicas de la Salud. Universidad de Caldas. Manizales, Colombia. Correo electrónico: jose.osorio_o@ucaldas.edu.co 